\title{
THE HISTOLOGY OF \\ THE LYMPHOID ORGANS OF RATS TREATED WITH ADRENOCORTICOTROPIN ${ }^{1}$
}

\author{
BURTON L. BAKER, DWIGHT J. INGLE AND CHOH HAO LI \\ Department of Anatomy, University of Michigan Medical School, Ann Arbor; \\ Research Laboratories, The Upiohn Company, Kalamazoo, Michigan; and \\ Department of Biochemistry, University of California, Berkeley \\ TWENTY-NINE FIGURES
}

\section{INTRODUCTION}

Many experimental observations have implicated the anterior hypophysis and adrenal cortex as being the source of the humoral factors which regulate the response of lymphoid tissues to noxious agents. Subjection of animals to any of a variety of stresses results in generalized lympboid atrophy (Selye, '46). Presumably, this effect is mediated at least partially by an accelerated secretion of adrenocorticotropin by the anterior hypophysis and, in turn, of C-11 oxygenated steroids by the adrenal cortex (Sayers and Sayers, '48). Similarly, when the concentration of these steroids in the body is elevated directly by injection of them, or indirectly by administration of adrenocorticotropin, there ensues a reduction in size of the thymus (Moon, '37; Ingle, '38, '40; Ingle, Higgins and Kendall, '38) and lymph nodes (Simpson, Li, Reinhardt, and Evans, '43) in the rat, and of the spleen (Molomut, Spain and Haber, '50) and thymus (Antopol, '50) in the mouse. Beyond these findings there remain a number of unanswered questions pertaining to the action of adrenocortical steroids on lymphoid tissues. This study, which deals with the micro-

\footnotetext{
1 Supported by grants-in-aid from the Division of Research Grants and Fellowships, United States Public Health Service, the J. G. Solomon Pilot Medical Research Fund, and from The Up.john Company. 
scopic changes which occur in lymphoid organs in a state of hyperadrenocorticalism induced by the injection of adrenocorticotropin, attempts to throw some light on these problems. In the first place, since it is established that treatment of rodents with adrenocorticotropin or C-11 oxygenated steroids induces a lymphopenia, more information is needed concerning the extent to which the lymphoid organs remain capable of producing lymphocytes when subjected to prolonged stimulation by the adrenocortical hormones. Thus, it is not clear whether the lymphopenia which develops in these situations is due to accelerated lymphocytolysis, retarded proliferation of the progenitors of lymphocytes, or to a combination of both factors. This information is important because of the postulation by Dougherty and White ('45) that under the action of the C-11 oxygenated adrenal steroids, the lymphocytes undergo lysis, liberate antibodies and increase the level of serum protein. Originally, they contended that electrophoretic patterns showed the increase in serum protein to be in the beta and gamma globulin fractions (White and Dougherty, '45) but more recently, Milne and White ('49) were unable to repeat these observations. On the contrary also, Eisen, Mayer, Moore, Tarr and Stoerk ('47) found repeated injection of adrenal extract into adrenalectomized rats to be without effect on the concentration of serum antibodies or gamma globulin and $\mathrm{Li}$ and Reinhardt ('47) observed no change in the serum protein after treatment with adrenocorticotropin. Although it has been reported that the injection of adrenocorticotropin (Dougherty, Chase and White, '45) and adrenocortical extract (Eisen et al., '47; Hammond and Novak, '50) will elicit an anamnestic response, Fischel, LeMay and Kabat ('49) failed to confirm these findings. In man, the partition of proteins as determined by electrophoresis and the level of antibodies in the serum remained unchanged after treatment with adrenocorticotropin (Forsham, Thorn, Prunty, and Hills, '48; Mason, Power, Rynearson, Ciaramelli, Li and Evans, '48; Sayers et al., '49; Herbert and De Vries, '49). It is hoped that clarification of the anatomical effects elicited in the lym- 
phoid organs by the adrenal hormones may help to resolve these conflicting reports.

Dougherty and White ('45) presented histological evidence of lymphocytic breakdown in the lymphoid organs of animals treated with adrenocorticotropin and explained the occurrence of lymphopenia on this basis. Several features of their investigations should be noted as a background for the experiments which we are reporting. The anatomical studies of Dougherty and White were concerned only with the changes elicited in the lymphoid organs by single or very short-term injections of adrenocorticotropin or the C-11 oxygenated steroids. Thus far, no investigation has been made of the cytological modifications which occur in lymphoid organs of animals injected repeatedly or continuously with adrenocorticotropin or adrenocortical steroids. Further, the anatomical experiments of Doughtery and White afford no information concerning the regenerative capacity of the lymphoid organs while they are being acted upon by adrenal steroids, nor do they clarify the structural capacity of lymphoid organs to maintain an increased production of lymphocytes under these eircumstances. More extensive exploration of the histological picture in lymphoid tissue under varying doses and periods of treatment is required before a general conclusion may be drawn concerning the importance of lymphocytolysis as a cause of lymphopenia or as a source of blood proteins. Finally, their studies were confined chiefly to the mouse and rabbit and little attenton was given to the rat.

Subsequent to the studies of Dougherty and White a number of workers attempted to demonstrate a direct lytic action of adrenocortical hormones on lymphocytes. This effect on lymphocytes was not observed in vitro with aqueous adrenal extracts (Robertson, '48) or 11-dehydrocorticosterone (Delaunay, Delaunay, and Lebrun, '49) but others reported accelerated aging (Schrek, '49) and increased susceptibility to lysis (Hechter and Johnson, '49; Feldman, '50) to be induced by certain adrenal extracts but not by the pure C-11 oxygenated compounds. These failures to demonstrate lysis 
of lymphocytes under the direct influence of adrenal hormones, coupled with the finding of Hechter and Johnson ('49) that the presence of a homogenate of lymphoid tissue promoted the lymphocytolytic action of adrenal extract in vitro led these authors to postulate the existence of a "co-factor" in lymphoid tissue which permits the breakdown of lymphocytes under the influence of adrenocortical hormones. This hypothesis emphasizes the importance of whatever cytological changes might occur in lymphoid organs coincident with the peripheral lymphopenia. In summary, present evidence indicates that the lymphoid tissue per se is the primary site where adrenal steroids induce lymphocytolysis.

Second, information concerning the effect of the adrenal cortex on the formation of lymphocytes has an important clinical bearing because it may help to clarify the manner in which administraton of adrenocorticotropin reduces the size of neoplastic growths in patients suffering from lymphosarcoma or Hodgkin's disease as has been reported by Pearson, Eliel, Rawson, Dobriner and Rhoads ('49). Biopsies of these tumors showed the disappearance of proliferative centers but no evidence of increased cell breakdown.

Third, the extent to which the hypophysis and adrenal cortex mediate the induction of lymphoid atrophy due to stress has not been revealed fully. The failure of some stresses including surgical trauma, starvation, and the injection of epinephrine or atropine (Selye, '50) to elicit this effect in the absence of the adrenal glands suggests that the secretions of the hypophysis and adrenal cortex are directly responsible for the lymphoid atrophy. Additional support would be derived from a demonstration that the pituitary adrenocorticotropic hormone induces microscopic changes similar to those brought about by stress. Baillif's ('49) recent exhaustive study of involution of the thymus resulting from treatment of rats with toxic doses of colloidal dyes provides an excellent basis for comparison, at least with respect to 
this organ. Therefore, our study has been concerned with this problem as well as with the effect of this hormone on the production of lymphocytes in lymphoid tissue.

\section{MATERIALS AND METHODS}

Adult, male Sprague-Dawley rats were used which weighed $300-320 \mathrm{gm}$ at the beginning of the experiment. The control rats gained in weight during the treatment period whereas those receiving adrenocorticotropin lost weight. In all experiments but no. 8, the animals were fed by stomach tube in order to eliminate inanition as a factor in causing the tissue responses to be described. Data pertinent to our experiments are summarized in table 1. Baker, Ingle, Li, and Evans ('48b) presented details on body weight changes and other information concerning the methods used in experiments 1 to 7 . For several years experimentalists working with adrenocorticotropin have realized the necessity of administering the hormone at frequent intervals in order to secure its maxmum effect. More recently, Greenspan, Li, and Evans ('50) showed that the half time of disappearance of adrenocorticotropin from rat plasma was only 5.5 minutes. Accordingly, in experiments 1 to 7 , the daily dose was administered in 8 divided injections. The development by Dr. Ingle of an apparatus for continuous subcutaneous injection has made possible a more satisfactory investigation of adrenocorticotropin and adrenocortical hormones. This equipment was utilized in experiments 8 to 11 and insured that the physiological potency of the adrenocorticotropic preparations was utilized to a maximal degree.

At autopsy mesenteric lymph nodes, the thymus and portions of the spleen were fixed in Zenker-acetic, Bouin's. or Carnoy's fluid. Sections of them were stained with Harris' hematoxylin and eosin, Regaud's iron hematoxylin and the Masson procedure, eosin and methylene blue (citric acid-disodium phosphate buffer), Dominici's procedure and by 
aqueous toluidine blue with mounting in $20 \%$ levulose for metachromasia. Some sections of spleens were stained by Perl's ferrocyanide reaction for ferric iron (Tillie, '47).

TABLE 1

Summary of experiments

\begin{tabular}{|c|c|c|c|c|c|c|c|c|}
\hline $\begin{array}{l}\text { Exp. } \\
\text { No. }\end{array}$ & $\begin{array}{l}\text { DAILY } \\
\text { DOSE }\end{array}$ & $\begin{array}{l}\text { DAYS } \\
\text { DURA- } \\
\text { TION }\end{array}$ & $\begin{array}{c}\text { NO. } \\
\text { RATS } \\
\text { TREATED }\end{array}$ & $\begin{array}{c}\text { No. } \\
\text { OF } \\
\text { CON- } \\
\text { TROLS }\end{array}$ & $\begin{array}{l}\text { MODF OF } \\
\text { INJECTIOS }\end{array}$ & $\begin{array}{l}\text { MANNER } \\
\text { OF FEED. }\end{array}$ & DI & $\begin{array}{l}\text { OPERATIVE } \\
\text { PROCEDURES }\end{array}$ \\
\hline & $m g$ & & & & & & & \\
\hline 1 & 1 & 21 & 3 & 3 & Int. S.C. & Tube ${ }^{1}$ & $\mathrm{C}, \mathrm{F}, \mathrm{P}=$ & \\
\hline 2 & 1 & 21 & 3 & 3 & Int. S.C. & Tube & $\mathrm{C}, \mathrm{F}, \mathrm{P}$ & \\
\hline 3 & 1 & 21 & 10 & 10 & Int. S.C. & Tube & $\mathbf{F}$ & \\
\hline 4 & 1 & 21 & 3 & 3 & Int. S.C. & Tube & Med. C & Castrated \\
\hline 5 & 3 & 21 & 3 & 3 & Tut. S.C. & Tube & $\mathrm{C}, \mathrm{F}, \mathrm{P}$ & \\
\hline 6 & 3 & 21 & 3 & 3 & Int. S.C. & Tube & $\mathrm{C}, \mathrm{F}, \mathrm{P}$ & \\
\hline 7 & 3 & 21. & 3 & 3 & Int. S.C. & Tube & Med.C & \\
\hline 8 & 3 & 21 & 6 & & Cont. S.C. & Ad. lib. & Med. C & $\begin{array}{c}\text { Hyp.; } 1 \text { adr. } \\
\text { enue. Other } \\
\text { out in } 3\end{array}$ \\
\hline 9 & 6 & 21 & 3 & 3 & Cont. S.C. & Tube & $\mathbf{F}$ & \\
\hline 10 & 6 & 21 & 1 & 2 & Cont. S.C. & Tube & $\mathbf{F}$ & \\
\hline 11 & 6 & 21 & 5 & . & Cont. S.C. & Tube & Med. C & $\begin{array}{l}1 \text { adr. enue. } \\
\text { Other ont } \\
\text { in } 2\end{array}$ \\
\hline 12 & 8 & 10 & 3 & 3 & Int. S.C. & Tube & $\mathrm{C}, \mathrm{F}, \mathrm{P}$ & \\
\hline 13 & 8 & 10 & 5 & 3 & Int. S.C. & Tube & $\mathrm{C}, \mathrm{F}, \mathrm{P}$ & \\
\hline
\end{tabular}

Int. - intermittent; S.C. - subcutaneous ; cont. - continuous; adr. - arlrenal; enuc. - enucleated; hyp. - hypophysectomized ; med. - medium.

'Stomach tube method of Reinecke, Ball and Samuels ('39).

"C - - high earbohydrate; F -. high fat; P.- hight protein. Composition given in Baker, Ingle, Li and Evans ('48b).

\section{OBSERVATIONS}

\section{Thymus}

Since other workers have dealt in detail with the histology of the normal thymus of the rat (Baillif, '49) little attention need be given it here. Baillif reviewed thoroughly the numerous points concerning the microscopic anatomy of the thymus which remain in dispute. With respect to the identity of the small parenchymal cell, we have chosen to designate it 
a thymocyte because of its questionable embryonic origin and the greater sensitivity exhibited by it to adrenocorticotropin than by the lymptocyte of other lymphoid organs. This latter observation will be developed more fully in a subsequent portion of our presentation.

Involution of the thymus was induced by adrenocorticotropin in all experiments and was so extensive that thymic tissue, per se, could not be identified macroscopically in the mediastinal fat. Only minor variation in the magnitude of this change existed from one experiment to another. Extreme involution followed treatment with the smallest dose employed, $1 \mathrm{mg}$ daily for 21 days administered by intermittent injections (figs. 1 and 2). Increasing the dose to $6 \mathrm{mg}$ daily supplemented by use of the technique of continuous injection resulted in only slightly greater atrophy. These observations indicated that the smallest dose of adrenocorticotropin which we used was well beyond the minimal level necessary to induce thymic involution and suggested that an increase in the daily dosage above $6 \mathrm{mg}$ given over a 21-day period would not obliterate the thymus completely.

Capsule and septa. The capsule of the normal thymus consisted of a thin layer of delicate fibers which stained with aniline blue and among which were occasional fibroblasts. Fibroelastic connective tissue was much more prominent in the septa than in the capsule. Staining with toluidine blue revealed frequent mast cells in both locations (fig. 5). By the use of intravital colloidal dyes Baillif ('49) was able to demonstrate the presence of many macrophages in the capsule. Not having used a comparable technique we found it most difficult to ascertain the frequency of occurrence of the capsular macrophages.

After treatment with adrenocorticotropin the thymus was seen microscopically to have been reduced to a thin strand of lymphoid tissue imbedded in fat. The lobular arrangement of the organ was preserved (fig. 2). Due chiefly to shrinkage of the parenchyma, the collapsed capsule thickened and the connective tissue composing it and the septa assumed a dense and somewhat homogenous texture (figs. 3 and 4 ). The homo- 
geneity was not referable to an increase in mucoid ground substance since aqueous toluidine blue failed to stain the connective tissue metachromatically. Hence, it must be assumed that the structure of the collagenous fibers had been modified. The concentration of mast cells was increased greatly in the capsule and septa due to reduction in the total volume of the organ (fig. 6). Practically all of the mast cells were heavily granulated. There was no evidence of an increase in their secretory activity or absolute number as a result of the hormonal treatment. Rarely was a mast cell observed in the parenchyma.

Parenchyma. All lobules of the involuted thymus were similar in that the volume of parenchyma was reduced. Within any one thymus, the lobules varied somewhat in the extent of atrophy which they had undergone. Areas were found in which cortex and medulla conld no longer be differentiated (fig. 3 ); in others the medulla was reduced to a narrow central strip containing few or no reticular cells and being identifiable only on the basis of the constituent blood vessels (fig. 4). Disintegrating medullary reticular cells were present frequently. If involution was not extreme, rather large numbers of thymocytes accumulated in the medulla at a time when they had practically disappeared from the cortex (figs. 5 and 6).

In the cortex, both of the two major elements, thymocytes and reticulum, were affected by adrenocortical activity. In severely involuted thymuses, thymocytes were removed almost completely from the parenchyma. In all cases, occasional isolated thymocytes could be found, which possessed either normal or pycnotic muclei. The absence of mitoses and scarcity of immature forms showed that thymocytes were not being replaced.

In most cases, some cortical reticulum remained after the thymocytes had been practically eliminated from this region. In less extremely involuted thymuses (experiment 3 ) the cortex was composed of densely arranged reticular cells, many of which seemed to be quite normal. Reticular cells became less numerous by undergoing several different types of modification. Many accumulated within their eytoplasm droplets 
of a homogeneous material which resembled colloid (fig. 7 ). This colloid exhibited exceedingly variable staining reactions. With eosin and methylene blue, it stained basophilically or not at all. With the Masson procedure the droplets assumed varying shades of blue to green or remained unstained. In certain instances the colloid droplets had coalesced and increased in number until the reticular cells became large ovoid giant cells filled with colloidal droplets of variable size. All stages in this transition were observed. The origin of the giant cells from reticulum seemed to be confirmed by the retention in them of a nuclear structure which was typical of reticular cells. Without doubt these cells are identical to the intra-lobular macrophages of Baillif ('49). The ultimate fate of these cells was not clearly defined in our material. Some seemed to disintegrate. Others may have reverted to reticular cells. If these cells were active macrophages, it is odd that we rarely found phagocytized nuclear and eytoplasmic particles within them, since so much degeneration was going on in their neighborhood.

In the most extremely involuted thymuses, actual degeneration of reticular cells was indicated by pyenosis of reticular cell nuclei. The nuclei of others assumed an elongated shape and internal structure which was indistinguishable from that of a fibroblast. Finally, even in the thymus of rats treated with $6 \mathrm{mg}$ of adrenocorticotropin daily by continuous injection, some reticular cells retained an epithelioid appearance and those directly beneath the capsule blended insensibly with capsular fibroblasts (fig. 3). Here, they were small and densely packed but gave no indication of degeneration.

Hassall's corpuscles occurred normally in the medulla of the rat thymus. Most of them were not as highly developed as those of man, since cells containing nuclei usually composed the center. Their incidence and number were quite variable. After treatment with adrenocorticotropin, Hassall's corpuscles were rarely found, particularly if the involution was severe. 
In the thymuses of control animals, cells were found in the cortex which possessed a basophilic cytoplasm. Some of the reticular cells and the large- and medium-sized thymocytes fell in this category. The presence of transitional forms indicated that these cells gave rise to plasma cells as well as thymocytes. Following involution only a few of the larger basophilic thymocytes remained. Their cytoplasm formed a thin deep blue rim around the large vesicular nucleus. Plasma cells were few in number (fig. 8) and there was no indication that they had multiplied under the influence of adrenocorticotropin.

\section{Spleen}

White pulp. As has been pointed out by others, the white pulp (Malpighian or splenic corpuscle) of the rat spleen consists of an inner (mantle) and outer (marginal) zone sepa. rated by a network of lymphatic channels constituting an intermediate sinus (Weidenreich, '01; Strasser, '22 ; Andrew, '46). Small, densely packed lymphocytes predominated in the inner zone and surrounded an excentrically placed artery. The nuclei of these cells were small with coarse chromatin particles. The outer zone was composed of larger cells, with lightly stained cytoplasm. The nuclei were larger and stained less intensely than those of the lymphocytes of the inner zone, and many of them possessed a wrinkled nuclear membrane. Internally the chromatin was finely dispersed and nucleoli were not prominent. Other workers have regarded these cells as being lymphocytes also.

The splenic corpuscles of all rats treated with adrenocorticotropin responded by reduction in caliber of the inner zone due chiefly to loss of lymphocytes from this region (figs. 9 and 10). The extent of this change was dependent on the dosage of adrenocorticotropin employed. One milligram daily for 21 days (experiments 3 and 4) was adequate to cause a moderate reduction in size of the majority of corpuscles with the inner zone of only an occasional corpuscle showing severe depletion of its lymphocytes. Practically all of the nuclei of the lymphocytes which remained were normal in structure (figs. 15 
and 16). At the 1 to $3 \mathrm{mg}$ doses as in most control spleens, secondary nodules ${ }^{2}$ were present in some of the splenic corpuscles. These regions contained macrophages and many mitotic figures. In all of these experiments, the outer zone showed far greater resistance to the action of adrenocorticotropin than did the inmer zone. The effect of $8 \mathrm{mg}$ daily for 10 days was similar to that found with the lower doses administered for a longer period of time.

Administration of 3 or $6 \mathrm{mg}$ of adrenocorticotropin daily by continuous injection induced a profound atrophy of the spleen (fig. 11). Grossly its color was a chocolate brown rather than the deep red of the normal spleen. Microscopically, the capsule was wrinkled and thickened. No secondary nodules were present and the caliber of the inner zone of all splenic corpuscles was reduced greatly (fig. 17). In most corpuscles, a few lymphocytes remained around the central artery but these were degenerating. This extreme involution of the inner zone was accompanied in this area by degeneration of the reticular connective tissue cells and an increase in the concentration of fibers which stained with aniline blue. Pigmentfilled macrophages seemed to be increased. The outer zone was thinner due to reduction in size and increased density of its cells, the nuclei of which possessed irregular shapes and many showed evidence of degeneration (fig. 17). Under these circumstances also, the outer zone showed more resistance to the cytolytic action of adrenocorticotropin than the inner zone and the changes occurring in it seemed to parallel more closely those to be described for the reticulum of the red pulp. Thus, when the inner zone was practically depleted of its lymphocytes, the lightly stained cells of the outer zone usually remained to mark out the location of the corpuscles (fig. 12).

\footnotetext{
2 The lightly stained areas which sometimes appear in the center of lymphoid nodules of the spleen and lymph nodes will be designated as "secondary nodules", for the reasons outlined by Bloom ('38). Our observations do not contribute to solution of the problem of whether seendary nodules are reaction centers, germinal centers, or a combination of both.
} 
Red pulp. The red pulp of the normal rat spleen is composed of vascular channels many of which are sinusoidal in structure. Between them is a loose reticulum in the interstices of which are found a wide variety of cellular elements. Sinusoids and blood were more prominent in the sub-capsular than central region of the organ. Scattered through the red pulp were occasional cord-like aggregations of lymphocytes.

At the lower doses of adrenocorticotropin very slight changes were induced in the red pulp. The total area of a section was reduced slightly (figs. 9 and 10). The moderate atrophy of the white pulp seemed to be insufficient to account for a reduction in the total size of the spleen and some decrease in the amount of blood contained in the red pulp appeared to be involved also. No structural changes were observed in the reticular cells or in the free cells contained in the interstices. Observations without making differential counts did not indicate more frequent pycnosis of lymphocyte nuclei than occurred in the control spleens. Accumulations of lymphocytes were slightly less prominent (fig. 10).

As in the white pulp, administration of 3 to $6 \mathrm{mg}$ of adrenocorticotropin daily by continuous injection amplified the extent of histological change in the red pulp, the general involution being as marked at $3 \mathrm{mg}$ daily as at 6 . This situation was observed in all treated rats of experiments $8,9,10$ and 11. The amount of blood traversing or being stored in the spleen was reduced greatly, in most cases the sinusoids obviously being non-functional. The erythrocytes which remained were generally not normal, staining poorly with eosin and appearing chiefly as ghosts. The sinusoids were collapsed, most of them being indistinguishable (figs. 18 and 19). The intervening reticular connective tissue was so densely packed that differentiation of cell types and determination of their structure proved to be most difficult. In general the reticular cells were smaller and their nuclei showed variable shapes and sizes, many being fragmented or undergoing pyenosis (fig. 17). However, it was clear that many reticular cells 
remained which were not damaged severely. Staining with the Masson or Perl's procedure showed that alteration in the number of macrophages containing pigment was quite variable.

A significant variation in the nature of the response of the red pulp to adrenocorticotropin occurred in the spleens of two of 6 rats which received $6 \mathrm{mg}$ daily by continuous injection (experiment 9). In these, also, most of the sinusoids were collapsed and contained only a few poorly stained erythrocytes. However, the spaces of the intervening reticular connective tissue were filled with hematopoietic cells which were spread diffusely throughout all of the red pulp (figs. 12 and 13). This general stimulation of blood cell formation in the splenic red pulp by adrenocorticotropin was not observed in any specimens from control animals or from any others treated with the hormone. Rapid proliferation of these cells was indicated by the presence of a multitude of mitotic figures (fig. 14). Many of the cells were hemocytoblasts whose size was greater than that of the reticular connective tissue cells. The eytoplasm was basophilic. The large nucleus contained scattered chromatin particles and one or more prominent nucleoli which sometimes assumed the shape of a bar.

Most of the cells found in the hematopoietic areas were erythroblasts characterized by a general basophilic cytoplasm and spherical nuclei with a checker-board chromatin pattern. Also seen frequently in preparations fixed in Carnoy's fluid and stained by Dominici's procedure were many normoblasts with pyenotic nuclei and distinct cell membranes which enclosed non-stainable cytoplasm. We concluded that the failure of the cytoplasm to stain with eosin was due to the same factors which caused the mature erythrocytes held in sinusoids of adrenocorticotropin-treated animals to appear as ghosts. A few polymorphonuclear leucocytes were found and formation of them was indicated by the presence of occasional immature forms with incompletely lobated nuclei. Plasma cells and some lymphocytes were identified also. Some megakaryocytes seemed to be enlarged and their cyto- 
plasm had lost much of its basophilia, staining lavender with toluidine blue.

Observation of microscopic sections of these spleens at low magnification, after staining with toluidine blue, suggested a reversal of the topographical pattern in so far as basophilia was concerned (figs. 12 and 13). In the spleens of the control rats, the densely packed lymphocyte nuclei made the inner zone of the splenic corpuscles far more basophilic than the blood-engorged red pulp. After treatment with $6 \mathrm{mg}$ daily of adrenocorticotropin the white pulp, as pointed out, was extensively depleted of its lymphocytes, leaving only the lightly stained cells of the outer zone as the predominant component (fig. 12). In contrast, the red pulp was deeply basophilic due to the presence of the hematopoietic cells described above.

\section{Lymph nodes}

Cortex. Under all conditions of treatment the cortex remained clearly demarcated from the medulla, but considerable atrophy of it was induced (figs. 20 and 21). The nodular pattern was retained although the nodules were smaller than in the controls. These regions had lost most of their lymphocytes, but many remained which, for the most part, possessed nuclei of normal structure, although they were smaller and more compactly arranged. Secondary nodules and mitotic figures were not present, indicating the absence of proliferation.

In the medulla, the reticular connective tissue network underwent extensive disintegration. The cells were shrunken and their nuclei were irregular in shape and frequently pycnotic. Reticular fibers were fragmented. Edema fluid and sometimes blood filled the medullary sinuses (fig. 25). The medullary cords, which normally contain large numbers of plasma cells, were less prominent. There was no increase in the absolute number of plasma cells. On the other hand, these cells seemed to be more resistant to the lytic action of adrenocorticotropin and, therefore, with the loss of lymphocytes they were proportionately more numerous in some cases. 
The changes described above occurred with the lowest dose of hormone employed. The severity of the involution was increased moderately by elevation of the dosage and employment of the continuous injection technique (figs. 21 and 23 ). When $3-6 \mathrm{mg}$ were given daily by continuous injection a few cortical nodules were still present (fig. 23) and in them the lymphocytes did not show evidence of breakdown and the reticular connective tissue cells seemed to be normal (fig. 22). Elsewhere in the cortex, reticular cells were swollen and vacuolated (fig. 27) or degenerating with pycnosis or karyorrhexis of the nucleus. Polymorphonuclear leucocytes infiltrated into these areas of degeneration. In the medulla some of the reticular connective tissue cells became filled with a hyaline, colloid-like material (figs. 24 and 25) while others disintegrated (fig. 26). The medullary cords were depleted of their cells so that in some nodes the small arterioles of the medulla became surrounded by a band of collagen containing only a few lymphocytes, plasma cells and fibroblasts (figs. 28 and 29). Occasional clusters of plasma cells remained, particularly in the hilar region or around arterioles entering the medulla. Free macrophages were reduced in number.

\section{Factors modifying the response to adrenocorticotropin}

The extent of lymphoid involution induced by adrenocorticotropin should be considered with respect to several variable factors which were present in these experiments. Thus, castration of three rats of experiment 4 one week prior to the initiation or hormonal treatment reduced the effectiveness of adrenocorticotropin, far less severe involution of all three lymphoid organs resulting than occurred in experiments 1 to 3 , the animals of which also received $1 \mathrm{mg}$ of the hormone daily for 21 days. Gonadectomy has been shown to result in lymphoid hyperplasia (Ross and Korenchevsky, '41) and the thymuses and lymph nodes in particular of the control rats in this series were hyperplastic. The nodes were enlarged with the cortex showing many actively proliferating 
secondary nodules and the medullary sinuses were engorged with lymphocytes. The thymus of none of the three castrated rats which received adrenocorticotropin was as extensively involuted as the thymus of rats in other experiments which received the same dose. The cortex of one thymus still retained thymocytes whereas in the other two the thymocytes had shifted to the medulla. In the latter two animals, the cortex remained as a cellular area composed of closely arranged reticular cells in which occasional mitoses were observed. These regions resembled somewhat the "parathyroidlike" epithelioid reticulum arising from hypertrophy and hyperplasia of the thymic reticular cells described by Selye ('50) to occur during the alarm reaction. However, in our specimens, the reticular cells were not hypertrophied and beyond their epithelioid appearance bore little similarity to the parathyroid parenchymal cells. In contrast to the latter cells, the cell membranes were quite indistinct. Nodules of epithelioid cells void of thymocytes were found imbedded in the thymic capsule and septa of both control and treated rats. Finally, the greater size of the lymphoid organs in castrated rats at the beginning of treatment may have been partially responsible for the failure of adrenocorticotropin to induce as great an involution as in non-gonadectomized rats. However, the possible participation of sex hormones in the action of adrenocortical steroids on lymphoid tissues requires further investigation.

In experiment 8, hypophysectomy resulted in some shrinkage of the spleen which appeared to involve chiefly the red pulp, little blood being found in the sinusoids. Many splenic corpuscles were present containing secondary nodules with frequent mitoses. Although the total amount of white pulp was reduced by removal of the hypophysis alone, administration of $6 \mathrm{mg}$ daily of adrenocorticotropin by continuous injection to these rats induced an involution of the spleen which was comparable in severity to that described previously for non-operated rats treated similarly with the hormone. Thus, hypophysectomy did not modify significantly the action of adrenocorticotropin on the spleen. 
The various lots of adrenocorticotropin were not always equally effective in causing lymphoid involution. Thus, with respect to the thymus, $1 \mathrm{mg}$ a day for 21 days did not induce as much change in experiment 3 as in experiments 1 and 2. The $3 \mathrm{mg}$ dosage of the hormone caused marked involution of the inner zone of the splenic corpuscles in experiment 7 but failed to do so in numbers 5 and 6 (fig. 16).

Under the conditions of these experiments, no evidence was secured that diet had a significant effect on the response of the lymphoid organs to adrenocorticotropin.

\section{DISCUSSION}

These observations throw some light on the cause of lymphopenia in hyperadrenocortical states. Our experiments were not designed to reveal the microseopic changes which occurred soon after the initiation of treatment. Dougherty and White ('45) have demonstrated that within a few hours after treatment of mice or rabbits with single doses of adrenocorticotropin, a general lymphocytolysis occurs in the lymphoid organs. It must be assumed that in our experiments, a similar effect occurred early in the period of treatment. In fact, the large proportion of the few remaining thymocytes and, to a lesser degree, of the medullary lymphocytes of the lymph nodes which possessed pycnotic nuclei after prolonged treatment, indicated that this influence was probably still operative after 21 days of treatment. On the other hand, our study of the histology of the lymphoid organs from animals treated with adrenocorticotropin shows clearly that the formation of new lymphocytes was curtailed sharply. As a consequence, few lymphocytes were produced which might undergo breakdown. Evidence supporting this view is as follows. Mitotic figures were generally absent from the thymus and lymph nodes after treatment with adrenocorticotropin. Lymphoblasts and other intermediate stages in the formation of thymocytes and lymphocytes were reduced greatly in number. In all of the lymphoid organs the ultimate progenitor of lymphocytes-the primordial reticular cells-underwent 
degeneration if adrenocortical stimulation was sufficiently intense.

The suggestion that growth-inhibition stands as the basic cause of lymphopenia under adrenocortical stimulation was made previously by Yoffey and Baxter ('46) and Robertson ('48) but, heretofore, convincing microscopic evidence has not been submitted. Our studies show that under continuous stimulation by adrenal steroids, lymphocytolysis in the lymphoid organs can be a significant phenomenon for a relatively brief period of time. Thus, the picture of growth inhibition which is evident in these organs is similar to that which characterizes other proliferating tissues including epidermis, hair, bone and cartilage in a state of hyperadrenocorticism (Baker, Ingle, Li and Evans, '48a; Baker and Ingle, '48; Baker and Whitaker, '48, '50; Baker, '49).

It seems reasonable to divide the period of prolonged stimulation of lymphoid tissue by the C-11 oxygenated adrenal steroids into two phases, the first being characterized chiefly by lymphocytolysis and the second, by failure in production of lymphocytes. Granting that the breakdown of lymphocytes provides serum protein and antibodies, this concept would explain why short-term treatment, as in the induction of the anamnestic response, may increase the concentration of these substances in the serum and prolonged treatment fails to do so. It follows, also, that if lysis of lymphocytes constitutes the only source of serum proteins and antibodies, an elevated production of neither could be maintained by extended treatment with adrenal hormones.

It should be emphasized that under the most intense adrenocortical stimulation employed in these studies, some apparently normal reticular cells were retained in each of the lymphoid organs studied. Regeneration certainly would have been possible upon cessation of treatment.

The active proliferation of hematopoietic cells in the red pulp of the spleen in two exceptional rats which received the heaviest dosage of hormone, stands as an exception to the conclusion that cellular proliferation is inhibited generally 
in the body. Further experimentation is needed to clarify the meaning of this observation. However, certain points merit attention. This prolifterative activity should not be regarded as a re-vtalization of successful lymphocyte production, since lymphocytes constituted only a small percentage of the cells present and most of the evidence pointed to the formation of the erythrocytes and granulocytes. The hematopoietic cells were scattered diffusely through the red pulp and bore no definite positional relationship to the splenic corpuscles which are regarded commonly as centers of lymphocyte production in the normal spleen. As will be discussed subsequently, evidence was secured of lowered resistance to infection in these rats. Therefore, hematopoeisis in the spleen may have resulted from this situation since erythropoiesis has been induced in the spleen by a variety of experimental procedures including the injection of certain bacteria (Klemperer, '38). It is possible, also, that the appearance of hematopoiesis in the spleen may be a compensatory response to the involution of marrow which occurred in some of the bones of these animals (Baker and Ingle, '48).

In rats which received lower doses of adrenocorticotropin it should be noted also that mitotic figures were observed in secondary nodules of the splenic corpuseles, in which the lymphocytes of the inner and outer zones showed no evidence of accelerated lymphocytolysis as indicated by their normal nuclear structure. Since it is not known whether secondary nodules arise as a reaction to toxins or serve as sites of lymphocyte proliferation (Klemperer, '38), at the present time, one cannot interpret this cellular proliferation in relation to the replacement of lymphocytes.

Differential response of lymphoid organs to adrenocorticotropin. Although the function of the thymus is unknown, some histologists hold that the small parenchymal cells of the thymus are different from lymphocvtes in general and have termed them thymocytes. This position is based on the possible epithelial origin of thymocytes. It is of interest, therefore, that in our studies the thymus was considerably 
more sensitive to the lytic action of the adrenal steroids than either the lymph nodes or the spleen. In most experiments, $1 \mathrm{mg}$ of adrenocorticotropin per day was adequate to induce thymic involution which was nearly as severe as that brought about by the highest doses of hormone administered by continuous injection. This involved almost complete destruction of thymocytes. On the contrary, in order to induce a comparable depletion of lymphocytes from the splenic corpuscles, the continuous injection of a minimum of $3 \mathrm{mg}$ a day was required. The lymph nodes of rats treated with still higher doses of the hormone retained cortical nodules composed of apparently normal lymphocytes. This difference in sensitivity of the lymphoid organs to adrenocorticotropin was demonstrated strikingly by several animals on the $3 \mathrm{mg}$ daily dose given by intermittent injection, which at the end of 21 days possessed an extremely involuted thymus (fig. 2) which was practically devoid of thymocytes and the nuclei of most of those which remained, were pycnotic. On the contrary, in the same rats the splenic corpuscles and cortical nodules of the lymph nodes were only moderately reduced in size (fig. 10) and lymphocytes with normal nuclei were present in both locations. This difference applies also to the reticulum as well as to the lymphocytes. The reason for this greater sensitivity on the part of the thymus is not clear but may be related to the fact that cellular proliferation is 4-6 times more rapid in the thymus than in the spleen and lymph nodes (Andreasen and Christensen, '49). Andreasen and Ottesen ('45) demonstrated also that the rate of turnover of desoxyribonucleic acid is about 4 to 5 times more rapid in the thymus than in the spleen and lymph nodes and during starvation the thymus undergoes greater atrophy than the spleen and lymph nodes and regenerates more slowly during re-feeding (Andreasen, '43).

Resistance to infection. The exact nature of the rôle played by lymphocytes in the defensive reactions of the body is not clear but obviously it is an important one. The function of the fixed and motile phagocytic cells of lymphoid organs in 
these processes is well-known. It follows that under intense adrenocortical stimulation, the lymphoid organs might become so atrophic that they would not be able to perform a protective function thereby lowering the resistance of the body to bacterial infection. Microscopic observation of the lymphoid organs indicates that such a condition has been created in these experiments. Proof for this statement was provided by the appearance of pulmonary abscesses and edema, myocarditis and pericarditis in some of our rats which were treated with the highest doses of adrenocorticotropin (Ingle and Baker, unpublished observations). Selye ('50) also observed pulmonary abscesses in rats treated with high doses of cortisone and Antopol ('50) found the appearance in the viscera of cortisone-treated mice of granulomatous nodules from which he cultured Corynebacterium pseudotuberculosis murium.

Information concerning action of adrenal hormones on the phagocytic activity of the reticulo-endothelial system is conflicting. Gordon and Katsch ('49) and Selye ('50) have reported accelerated phagocytosis to result from treatment of animals with these hormones. In contrast, Spain, Molomut and Haber ('50) found cortisone to retard the phagocytic response in mice. In our experiments no dyes were injected for the study of phagocytosis. However, few macrophages which contained ingested cell particles were present in the lymphoid organs, particularly in the thymus. This finding in addition to the ultimate degeneration of reticulum with reduction in number of macrophages which was induced by intense adrenocortical stimulation, indicated that under these circumstances the phagocytic power of lymphoid organs was impaired. The discrepancies between this conclusion and that of other investigators may be due to variation in the dosages and periods of treatment to which the animals were subjected.

It is of interest that in both the involuting thymus and lymph node, reticular cells became filled with colloidal material. In the former organ the reticular cells were transformed into giant cells which Baillif ('49) designated as 
intra-lobular macrophages on the basis of the appearance of colored colloid in these cells after previous injection of colloidal dyes into the animal. This he interpreted to have been brought about by phagocytic activity on the part of the cells. His studies did not demonstrate whether such cells arise in the absence of exogenous colloid. Our observations show that they do when involution is induced by hormonal means, but the origin or significance of the colloid was not revealed. Possibly degenerating tissue is digested extracellularly and the products of this digestion then absorbed by these cells and held as colloid. The great variation in affinity of this colloid for stain was observed in this study as well as by Baillif. In the lymph nodes the development of intracellular colloid is clearly a concomitant part of a degenerative process. The nuclei of the colloid-containing cells lost their normal morphology and many were fragmenting. The cells themselves decreased in size as the colloid developed in their cytoplasm.

Dougherty and White ('46) reported that single injections of adrenocorticotropin into rabbits stimulated the production of plasma cells. In none of our preparations did we make similar observations in the rat. As is well known, plasma cells constitute a large proportion of the cellular constituents in medullary cords of lymph nodes and are found in considerable numbers around blood vessels of the hilus. Our preparations indicated that plasma cells were more resistant than lymphocytes to the destructive action of adrenal steroids so that under moderate dosage, plasma cells seemed only relatively more numerous. If the intensity of hormonal treatment was increased, plasma cells were depleted from the lymph nodes.

It appears that treatment of rats with adrenocorticotropin duplicated rather closely the changes which occur in the lymphoid organs under stress except that the hormone caused more severe modifications. During lymphoid involution resulting from stress (Selye, '50), the thymus responds more intensely than any of the other lymphoid organs studied. No 
structural modifications were observed in the thymuses from our experiments which differed significantly from those described by Baillif ('49) to result from the administration of toxic colloidal dyes to rats. Other changes have been described in the thymus of rats subjected to various types of stress which did not appear in our specimens. Selye ('36) observed edema, hemorrhage and epithelial proliferation, the latter effect having been found also by Ross and Korenchersky ('41) after treatment with estrogen. It is possible that in our experiments adrenocorticotropin had carried thymic involution beyond a point where these modifications might have been observed. The alterations which occur in the lymph nodes and spleen vary considerably according to the type of stress brought to bear on the animal. This situation makes it difficult to compare these effects with those induced by adrenocorticotropin. For example, enlargement of the spleen occurs in many infections. However, in non-infectious stresses, involution of the spleen occurs during the alarm reaction with the white pulp being affected more than the red pulp (Selye, $50)$. In the lymph nodes a severe alarm reaction may induce complete disappearance of secondary nodules. Although more detailed cytological studies of lymph nodes and spleen during stress would be desirable, on the basis of available information the changes which follow stress are closely similar to those induced by adrenocorticotropin. Thus, it would appear that our observations add further support to the concept that the pituitary-adrenal axis mediates most of the effects elicited in the lymphoid system by stress. But it should be noted that Herlant ('50) recently demonstrated a karyoclastic action of stress on the thymus of rats in the absence of the adrenal glands, when a dose of adrenocortical extract, which by itself would not induce lymphocytolysis, was administered concurrently. This is another illustration of the principle advanced by Ingle, Ward and Kuizenga ('47) that under some circumstances the adrenocortical steroids serve only to permit or support the action of other factors on the tissues of the body rather than serving as the agent which directly effects mobili- 
zation. In their work adrenocortical hormones were shown to permit the mobilization of body proteins. In conclusion, it seems clear that the adrenal steroids secreted under the influence of adrenocorticotropin have a direct effect on the lymphoid organs, but determination of the relative significance of their indirect or supportive role in stress requires additional investigation.

\section{SUMMARY}

In male rats treated with pure adrenocorticotropin for periods up to 21 days production of lymphocytes or thymocytes was impaired as shown by the absence of mitotic figures, reduction in number of transitional cell forms and ultimate partial destruction of the reticular cells. Possibly because of the absence of large numbers of lymphocytes resulting from this defect, lymphocytolysis was not a prominent characteristic of the lymph nodes and spleen, although it did occur. The cytological changes which appeared in the thymus were similar to those reported to be elicited by stress. The thymus was more sensitive to the action of adrenocorticotropin than were the lymph nodes and spleen. Whereas thymocytes were removed almost completely from the thymus by a $1 \mathrm{mg}$ daily dose, 3 or $6 \mathrm{mg}$ administered by continuous injection was required to deplete the splenic corpuscles of their lymphocytes. Under the latter treatment there developed a profound general involution of the spleen with an apparent termination in function of the sinusoidal system, little blood being found either in the sinusoids or in the interstices of the intervening reticular tissue. Hematopoiesis occurred in the red pulp of spleens from two rats which received $6 \mathrm{mg}$ of adrenocorticotropin daily by continuous injection. In the lymph nodes of rats similarly treated, cortical nodules were still present and contained lymphocytes of practically normal nuclear structure. No increase in plasma cell production was observed in any of the lymphoid organs studied. 


\section{LITERATURE CITED}

Andreasen, E. 1943 Studies on the thymolymphatie system. Acta Path. et microbiol. Scand. Suppl., 49:1-171.

Andreasen, E., and S. Christensen 1949 The rate of mitotic activity in the lymphoid organs of the rat. Anat. Rec., 103: 401-412.

Andranase, E., ANd J. Ottesen 1945 Studies on the lymphocyte production. Investigations on the nuclei, acid turnover in the lymphoid organs. Acta Physiol. Scand., 10: 258-270.

ANDREw, W. 1946 Age changes in the vaseular architecture and cell content in the spleens of 100 Wistar Institute rats, including comparisons with human material. Am. J. Anat., 79: 1-74.

Antopol, W. 1950 Anatomic changes produced in mice treated with excessive doses of cortisone. Proc. Soc. Exp. Biol. and Med., 7s: 262-265.

BAILLIF, R. N. 1949 Thymic involution and regeneration in the albino rat, following injection of acid colloidal substances. Am. J. Anat., 84: $457-510$.

BAKER, B. L. 1949 Modification of body strueture by adrenocortieal secretions with special reference to the regulation of growth. A.A.A.S. Symposium on the Adrenal Cortex. In press.

BAKER, B. L., AND D. J. INGLE 1948 Growth inhibition in bone and bone mar. row following treatment with adenocorticotropin (ACTH). Endocr., 43: $422-429$.

BaKer, B. L., D. J. IngLe, C. H. LI AND H. M. Evans 1948a Growth in. hibition in the skin induced by parenteral administration of adenocorticotropin. Anat. Ree., 102: 313-332.

$1948 \mathrm{~b}$ The effect on liver structure of treatment with adrenocorticotropin under varied dietary conditions. Am. J. Anat., 89: 75-103.

BaKer, B. L., AND W. L. Whitaker 1.948 Growth inhibition in the skin following direct application of adrenal cortical preparations. Anat. Rec., 10\%: $333-347$.

1950 Interference with wound healing by the local action of adrenocortical steroids. Endocr., $46: 544-551$.

BLoom, W. 1938 Lymphatic tissue; lymphatic organs. Handbook of Hematology. Ed. by H. Downey, Paul B. Hoeber, Ine., New York. Chap. $\mathrm{XIX}, 1427-1467$.

Delaunay, A., M. Delaunay and J. Lebrun 1949 Lesions et reactions du tissu 1ymphoide. Ann. Inst. Pastenr, $76: 203-220$.

Dovgherty, T. F., J. H. Chase AND A. White 1945 Pitnitary-adrenal cortical control of antibody release from lymphocytes. An explanation of the anamnestic response. Proc. Soc. Exp. Biol. and Med., 58: 1.35-140.

DovgherTY, T. F., AND A. WhiTe 1945 Functional alterations in lymphoid tissue induced by adrenal cortical secretion. Am. J. Anat., 77 : 81-116. 1946 Inereased "plasma cell" production following adrenal cortical stimulation. Anat. Rec., 94 (Suppl.): 13-14.

Ersen, H. N., M. M. Mayer, D. H. Moore, R. R. Tarr aNd H. C. Stoerk 1947 Failure of adrenal cortical activity to influence circulating antibodies and gamma globulin. Proc. Soc. Exp. Biol. and Med., 65: 301-306. 
Fridian, J. 1. 1950 The in vitro reaction of cells to adrenal cortical steroids with special reference to lymphocytes. Endocr., 46: 552-562.

Fischel, E. E., M. IJMAY AND E. A. KABAT 1949 The effect of adrenocortico. trophic hormone and $x$-ray on the amount of circulatng antibody. J. Inımun., 61: 89-93.

Forsham, P. H., G. W. Thorn, F. T. G. Prunty and A. G. Hills 1948 Clinical studies with pitutary adrenocorticotropin. J. Clin. Endocr., 8 : 15-66.

Gondon, A. S., AND G. F. KATSCH 1949 The relation of the adrenal cortex to structure and phagocytic activity of the macrophagic system. Ann. N. Y. Acad, Sci., 52: 1-30.

Greenspan, F. S., C. H. Li ANd H. M. Evans 1950 Disappearance rate of adrenocorticotropic hormone from rat's plasma after intravenous injection. Endocr., 46:261-264.

Hammond, C. W., ANd M. Novak 1950 Relation of adrenal cortical steroids to antibody release. Proc. Soc. Exp. Biol. and Med., 74: 155-161.

HECHTER, O., AND S. JoHNSON 1949 In vitro effect on adrenal cortical extract upon lymphocytolysis. Endocr., 45: 351-369.

Herbert, P. H., and J. A. DE VRIEs 1949 The administration of adrenocorticotrophic hormone to normal human subjects. The effect on the lencocytes in the blood and on circulating antibody levels. Endoer., 44: $259-273$.

Herlant, M. 1950 Conditioning, through stress, of the action of corticoids on lymphoid organs. Proc. Soc. Exp. Biol. and Med., 73: 399-401.

INGLE, D. J. 1.938 Atroply of the thymus in normal and hypophysectomized rats following administration of cortin. Proc. Soc. Exp. Biol. and Med., 38: 443-444.

1940 Effect of two steroid compounds on weight of thymus of adrenalectomized rats. Proc. Soc. Exp. Biol. and Med., 44: 174-175.

Ingle, D. J., G. M. Higgins ANd E. C. Kendall 1938 Atrophy of the adrenal cortex in the rat produced by administration of large amounts of cortin. Anat. Rec., 71: 363-372.

INGLe, D. J., E. O. WARD AND M. H. KuIZENGA 1947 The relationship of the adrenal glands to changes in urinary non-protein nitrogen following multiple fractures in the force-fed rat. Am. J. Physiol., 149: 510-515.

Klemperer, P. 1938 The spleen. Handbook of Hematology. Ed. by H. Downey, Paul B. Hoeber, Jne., New York. Chap. XXI, 1589-1754.

LI, C. H., AND W. O. REINHARDT 1947 Electrophoresis of rat plasma. II. The effect of adrenocorticotropic hormone. J. Biol. Chem., 167: 487-493.

LILlIE, R. D. 1947 Histopathologic Technic. The Blakiston Company, Philadelphia.

Mason, H. L., M. H. Power, E. H. Rynearson, L. C. Ciaramgiti, C. H. Li and H. M. EvaNs 1948 Results of administration of anterior pituitary adrenocorticotropic hormone to a normal human subject. J. Clin. Endocr., $8: 1-14$

Milne, J., AND A. WHITE 1949 Effect of adrenal cortical extract and $x$ radiation on serum proteins of mice. Proc. Soc. Exp. Biol. and Med., 79: 424-498. 
Molomu's, N., D. M. SPAIN AND A. HABER 1950 The effect of eortisone on the spleen in mice. Proc. Soc. Exp. Biol. and Med., 73: 416.

Moon, H. D. 1937 Inhibition of somatic growth in eastrate rats with pituitary extracts. Proc. Soc. Exp. Biol. and Med., 37: 34-36.

Pearson, O. H., L. P. Eliel, R. W. Rawson, K. Dobriner and C. P. Rhoads 1949 ACTH- and cortisone-induced regression of lymphoid tumors in man: a preliminary report. Cancer, $2: 943-945$.

Reinecke, R. M., H. A. Ball and L. T. Samuels 1939 High fat and high carbohydrate diets that can be fed to rats by stomach tube. Proc. Soc. Exp. Biol. and Med., 41: 44-46.

Robertson, J. S. 1948 Failure of adrenal cortical extracts to cause lysis of living lymphoeytes in vitro. Nature, 161: 814.

Ross, M. A., AND U. KoneNCHEvsky 1941 The thymus of the rat and sex hormones. J. Path. and Bact., 5\%: 349-360.

SAyers, G., AND M. A. SAYers 1948 The pituitary-adrenal system. Recent progress in hormone research. Acad. Press, Inc., N. Y., $2: 81-115$.

Sayers, G., T. W. Burns, F. H. Tyler, B. V. JAger, T. B. Schwartz, E. L. Smith, L. 'T. SAMUels AND H. W. Davenpor'y 1949 Metabolic actions and fate of intravenously administered adrenocorticotropic hormone in man. J. Clin. Endoer., $9: 593-614$.

SchreK, R. 1949 Cytotoxic action of hormones of the adrenal cortex according to the method of unstained cell counts. Endoer., 45: 317-334.

SELYF, H. 1936 Thymus and adrenals in the response of the organism to injuries and intoxications. Brit. J. Exp. Path., 17: 234--248.

1946 The general adaptation syndrome and the diseases of adaptation. J. Clin. Endoer., 6: 117-230.

1950 Stress. Acta Ine., Montreal.

Simpson, M. E., C. H. II, W. O. Reinhardt and H. M. Evaxs 1943 Similarity of response of thymus and lymph nodes to administration of adrenocorticotropic hormone in the rat. Proe. Soc. Exp. Biol. and Med., 54: $135-137$.

Spain, D. M., N. Molomut and A. Haber 1950 Biological studies on cortisone in mice. Science, 112: 335-337.

Strasser, U. 1922 Zur hamosiderosefrage nebst Beitragen zur Ortho- und Pathohistologie der Milz. Beitr. f. Path. Anat., 70: 248-264.

Weidenreich, F. 1901 Das Gefassystem der menschlichen Milz. Arch. f. Mikr. Anat., $58: 247-376$.

WhiTe, A., AND T. F. DOUGHERTY 1945 The pituitary adrenotrophic hormone control of the rate of release of serum globulins from lymphoid tissue. Endoer., 36: 207-217.

YoFfEy, J. M., AND J. S. BAX'TER 1946 Some effects of pituitary adrenotropic (PATH), extract of suprarenal cortex, and colchicine on the haemopoietic system. J. Anat., 80:132-138. 


\section{PLATE 1}

\section{EXPLANATION OF FIGURES}

I Thymus, control for figure 2. Lobular arrangement and differentiation of cortex and medulla are shown. Hematoxylin and eosin. $\times 23$.

2 Thymus of rat on a high carbohydrate diet which received $3 \mathrm{mg}$ of adrenocorticotropin daily for 21 days by intermittent injection. Involution has occurred, the lobular arrangement being preserved. At this magnification, cortex cannot be differentiated from the medulla. Technique as in figure 1.

3 Thymus of rat which received $6 \mathrm{mg}$ of adrenocorticotropin daily for 21 days by continuous injecton. The figure extends across an entire lobule. The cortex cannot be differentiated from medulla in this area. The pycnotic nuclei of a few seattered thymocytes are seen. Seemingly normal nuclei of reticular cells (fibroblasts?) are present and are especially numerous along the inner border of the capsule (black line). These nuclei are quite similar to those of fibro. blasts (arrow) in the capsule. The capsule is below the black line and is thickened considerably. Regaud's hematoxylin and Masson. $\times 400$.

4 The same section of thymus as that illustrated in figure 3 , showing atrophic but vascular medulla and thickened capsule in the lower part of the field. Technique as in figure 3.

5 Thymus of a control rat showing scattered mast cells in the capsule (arrow). Eosin and methylene blue. $\times 90$.

6 Partially involuted lobule of the thymus of a rat on a high protein diet, which received $1 \mathrm{mg}$ of adrenocorticotropin daily for 21 days. The concentration of mast cells is increased in the capsule and septa. Thymocytes are more numerous in the medulla than in the cortex. Technique as in figure 5 . 
B. L. BAKER, D. J. INGLE AND O. H. LI
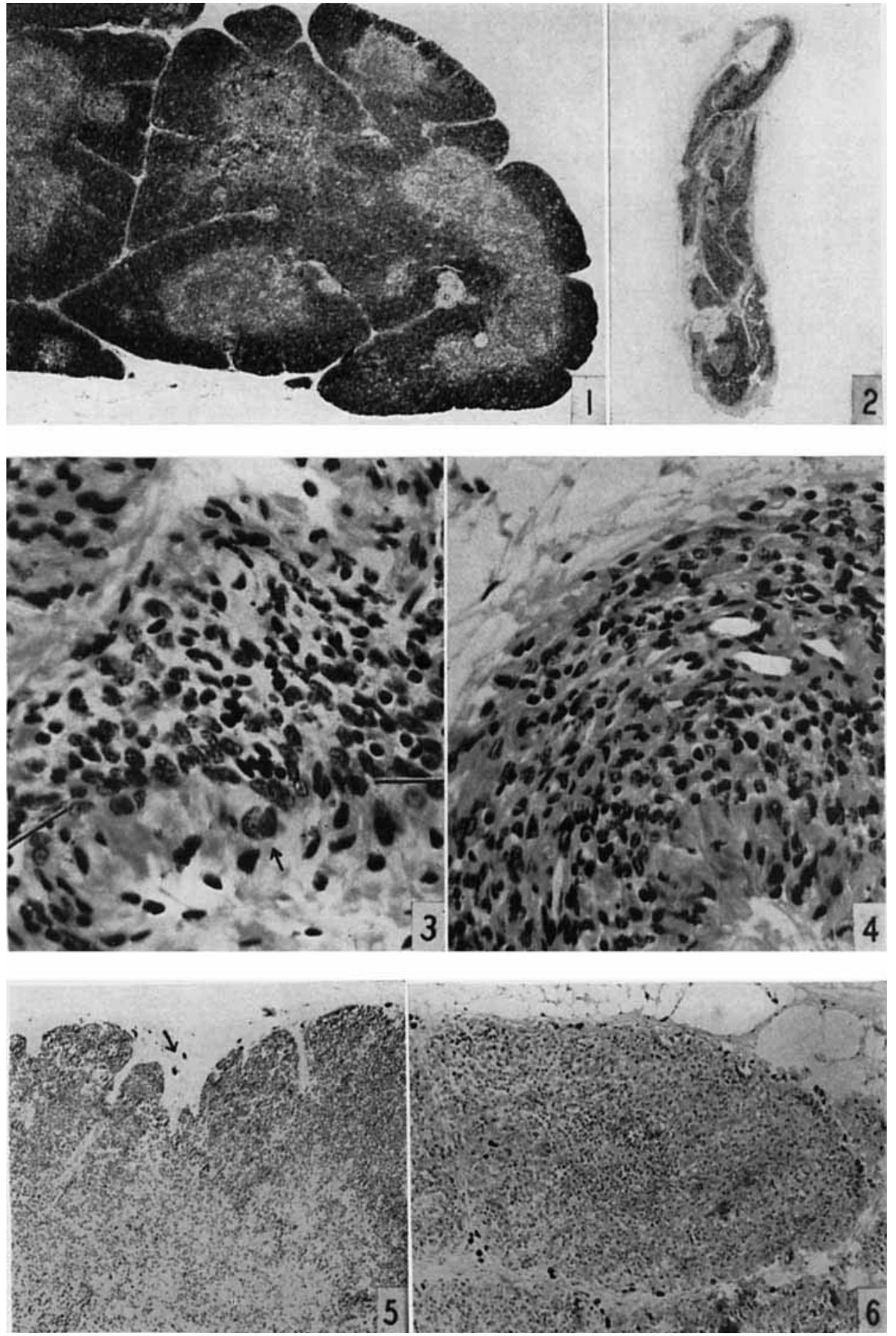
PIATH 2

\section{FXPLANATION OF FIGURES}

7 Involuted thymus illustrating reticular cells which have become filled with colloid, a giant cell being located in the center. The nuclear structure in this cell is similar to that of reticular cells in general. Eosin and methylene blue. $\times 925$.

8 Same section as that illustrated in figure 7 . A few plasma cells (arrow) are scattered among medium-sizcd thymocytes and reticular connective tissue.

9 Spleen from a rat whose thymus is illustrated in figure 1 . Splenic corpuscles are numerous and large, their lighter outer zoile being differentiated from the dark inner zone. Regaud's Hematoxylin and Masson. $\times 27$.

10 Spleen from a rat whose thymus is illustrated in figure 2. Moderate reduction in sizo of the spleen has occurred. The splenic corpuscles are reduced in number but many are still comparatively normal in structure (see fig. 16). Technique as in figure 9 .

11 Spleen from a rat on a high fat diet which received $6 \mathrm{mg}$ of adrenocorticotropin daily for 21 days by continuous injection. Extensive involution has occurred. The splenic corpuscles are marked out by their atrophic outer zone. The inner zone is depleted almost completely of lymphocytes. The density of the red pulp is increased. Technique as in figure 9 .

12 Spleen from a rat which had received $6 \mathrm{mg}$ of adrenocorticotropin daily for 21 days by continuous injection. The lightly stained central area is the atrophic outer zone of a splenic corpusele. Only a few small lymphocytes of the inner zone remain around the central artery which appears in several locations. The red pulp is infiltrated diffusely with deeply basophilic hematopoietic cells. Dominei's stain. $\times 60$.

13 Spleen, control for figure 12. The splenic corpuscles show distinct inner and outer zones. Some cord-like aggregations of lymphocytes are present in the red pulp. Technique as in figure 12 . 
B. I. RAKUR. D. J. INGLb AND C. H. J.I



\section{PLATE 3}

\section{EXY'AANATION OF FGURL}

14 Hematopoiesis in the spleen which was illustated in figure le from a rat treated with adrenocorticotropin. Some of the largest eells are hemocytoblasts with basophilic eytoplasm. Most of the numerous pyenotic nuclei belong to normoblasts and are surrounded by clear eytoplasm. Mitotic figures are present (arrows). The lightly stained cells in the upper part of the figure compose the outer zone of a splenic corpuscle. Dominici's stain. $\times 440$.

1.5 Splenic corpusele from a spleen which is the control for that illustrated in figure 17. A lightly stained reaction center is in the lower part of the field. The lines point to the intermediate sinus which separates the outer zone above from the denser inner zone below. The lnter contuins many mature lymphocytes. Regaud's hematoxylin and Masson. $\times 270$.

16 Splenic corpuscle from the spleen of an adrenocorticotropin-treated rat whose thymus is illustrated in figure 2. A reaction center with mitotic figures (arrow) is in the lower part of the field. The inner and outer zones are changed very little as compared with the control picture as illustrated in figure 15 . Technique as in figure 15 .

17 Splenic corpuscle from a rat which received $6 \mathrm{mg}$ of adrenocorticotropiu daily for 21 days by continuous injection. The central artery is in the conter of the figure. The inner zone is almost completely atrophic, only a few lymphoeytes remaining in the connective tissue around the artery. Remnants of the loosely arranged outer zone are seen in the upper part of the figure. Some of the nuclei are pycnotic or fragmented. Technique as in figure 15. 
B. L. RAKHR, 1., J. INCLLAS AND C. H. LI
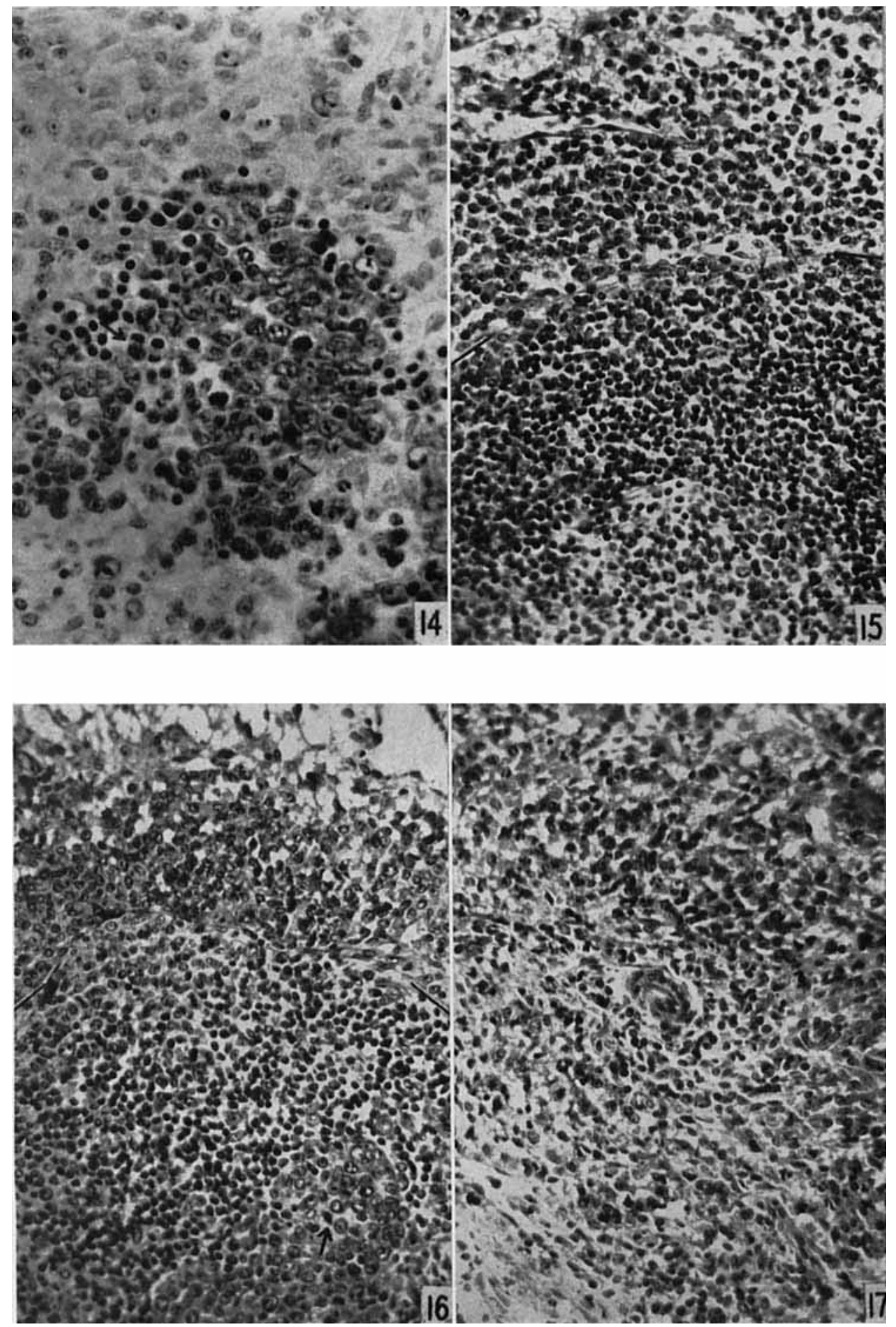
PLATE 4

EXPLANATION OF FIGULES

18 Red pulp of a splecn which is a control for that illustrated in figure 19. The sinusoids and interstices of the intervening connective tissue are filled with blood. Regaud's hematoxylin and Masson. $\times 330$.

19 Splenic rod pulp from a rat which had received $6 \mathrm{mg}$ of adrenocorticotropin daily for 21 days by continuous injection. Blood is almost totally absent from the sinusoids and connective tissue spaces. Technique as in figure 18 .

20 Lymph node, control for figure 21. Cortex and medulla are differentiated clearly. Regaud's hematoxylin and Masson. $\times 31$.

21 Lymph node, $3 \mathrm{mg}$ of adrenocorticotropin daily for 21 days by intermittent injection, medium carbohydrate diet. Some reduction in size of the node las oceurred, with the number of lymphocytes in the cortex being reduced. Medullary cords are still visible. Technique as in figure 21.

22 Cortical nodule indieated by the arrow in figure 23 from an adronocorticotroyin-treated rat. $\Lambda$ cluster of pigment-laden eclls is at the left. No mitoses are present and the mature lymphocytes, their progenitors and reticular conncctive tissue cells do not show much evidence of degeneration. Regaud's hematoxylin and Masson. $\times 550$.

23 Lymph node of a rat which received $6 \mathrm{mg}$ of adrenocorticotropin daily for 21 days by continuous injection. The extent of involution is only moderately greater than that shown by the node ilhustrated in figure 21 . Technique as in figure 20 . 


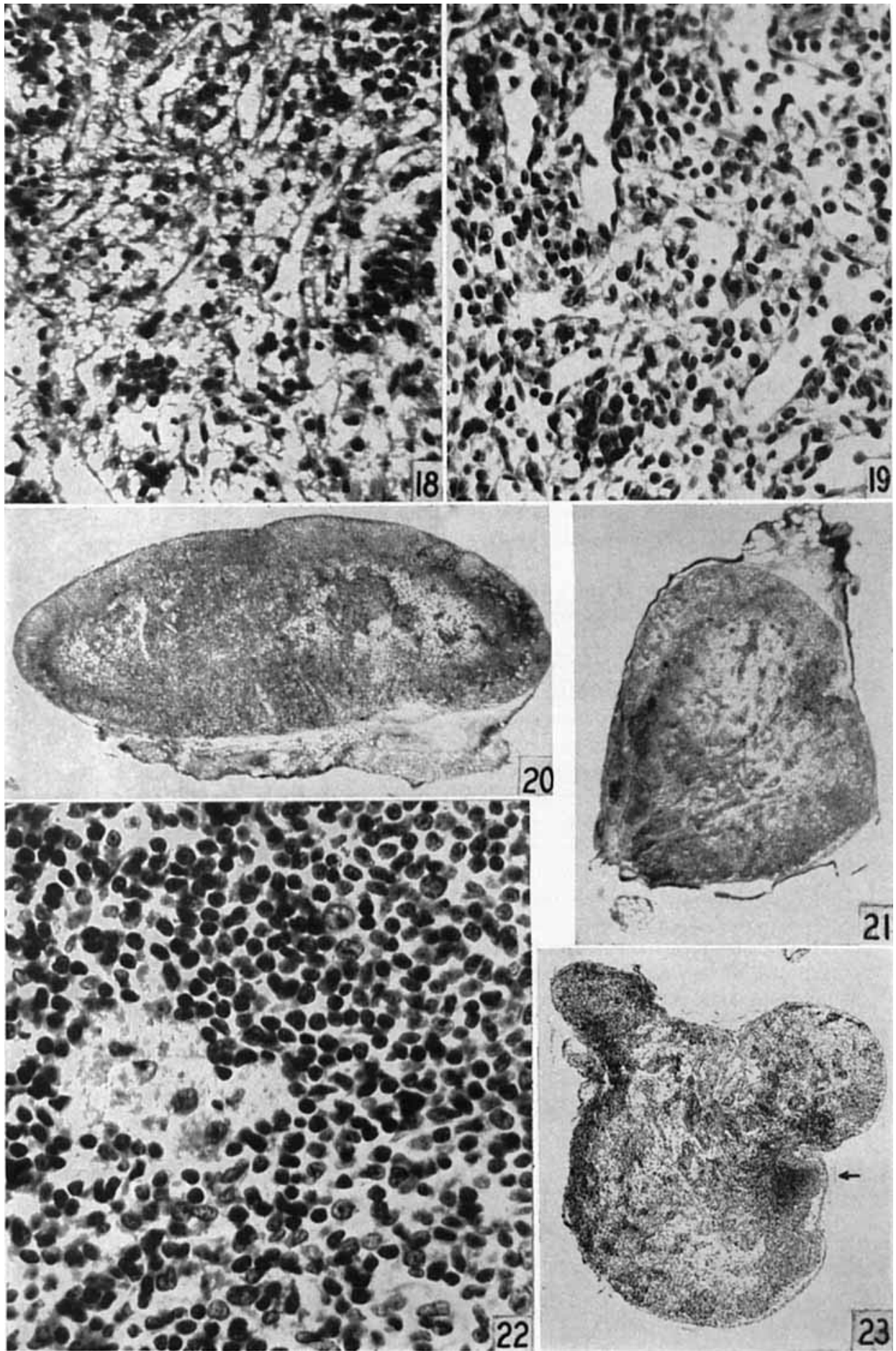




\section{PLATE 5}

EXPLANATION OF FIGURES

24 Lymph node, control for figures 25 and 26. A portion of a medullary cord is at the right. Centrally are several large reticular cells with numerous cytoplasmic processes. Regaud's hematoxylin and Masson. $\times 500$.

25 Medullary reticulum in the lymph node of a rat which received $6 \mathrm{mg}$ of adrenocorticotropin daily for 21 days by continuous injection. The cytoplasm of the reticular cells is filled with colloid and many of their nuclei are shrunken and distorted. The medullary sinus contains edema fluid. Technique as in figure 24.

26 Another area of the medulla of the node illustrated in figure 25. Ifore the eytoplasm of the reticular cells is disintegrating and the nuclei are pyenotic. Technique as in figure 24.

27 Cortical reticulum of the node illustrated in figures 25 and 26 . At the left are some swollen reticular cells. Scattered throughout the area are nuclear fragments as well as polymorphonuclear leucocytes which have infiltrated into the area. Regaud's hematoxylin and Masson. $\times 900$.

28 Medullary cord and sinus of lymph node, control for figure 29. The cord is composed chiefly of plasma cells and lymphocytes. In the sinuses are several motile macrophages as well as lynphocytes and reticular connective tissue cells. Regaud's hematoxylin and Masson. $\times 630$.

29 Medullary cord of lymph node illustrated in figures 25,26 and 27 taken from an adrenocorticotropin-treated rat. Plasma cells are removed almost completely from the cord and only a few lymphocytes and degenerating cells remain. Connective tissue fibers are relatively more prominent than in the medullary cord of figure 28 . The sinus is filled with edema fuid, macrophages are less numerous and the reticulum appears to be regenerating. Technique as in figure 29. 
H. L. BAKER, D. J. INGLLV ANB C. H. I.I
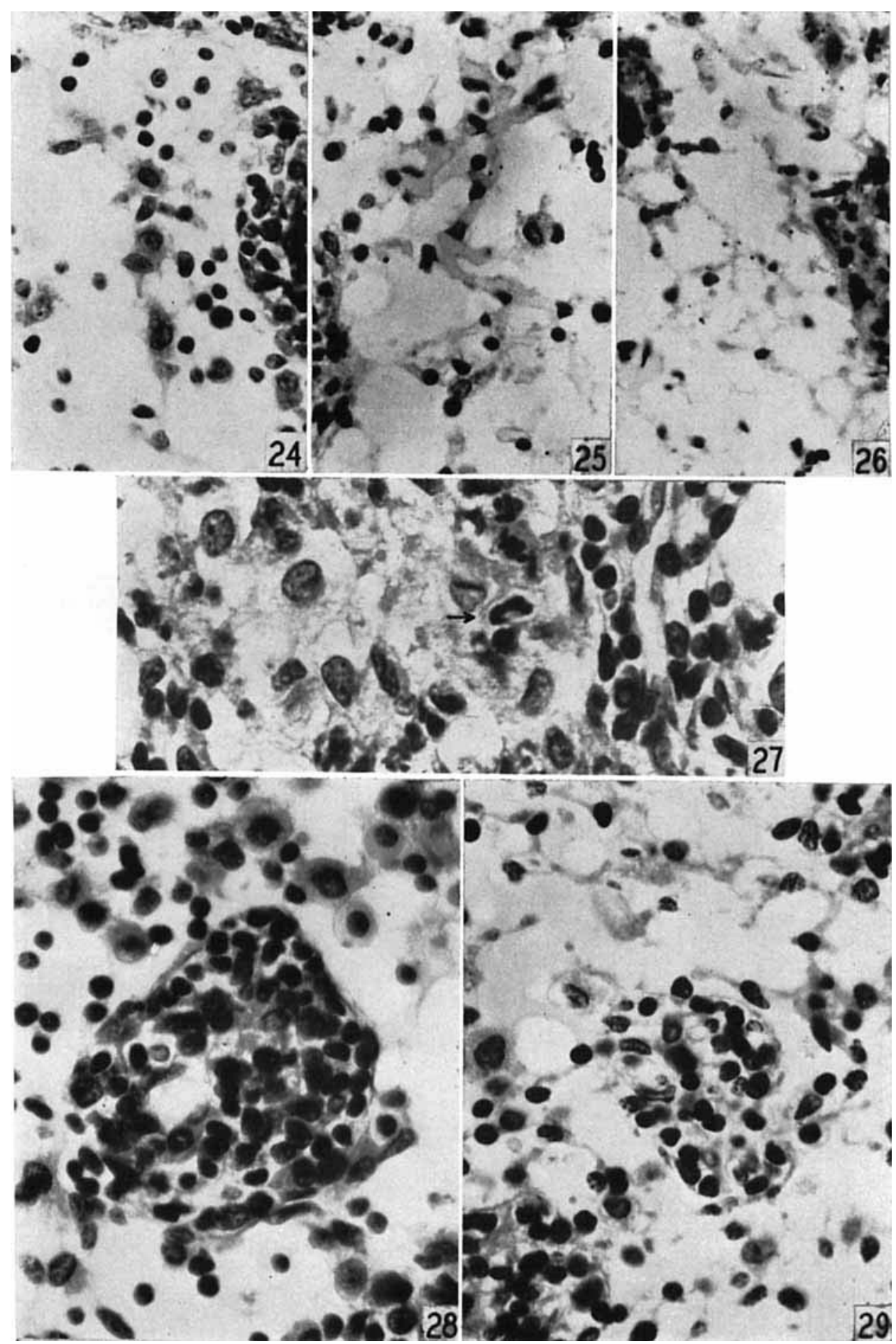